\title{
The Relationship between Organisational Psychology and Career Decision: A Study of Hospitality and Tourism Professionals
}

\author{
Luis M. Dos Santos \\ Woosong University, \\ 196-5 Jayang Dong, \\ Daejeon, South Korea
}

DOI: https://doi.org/10.36941/ajis-2021-0o61

\begin{abstract}
Hospitality and tourism management is one of the rapid growth industries over the decades due to transportation developments. However, a significant concern of the current hospitality and tourism industry is frequent and high-level of employee turnover rate. The hospitality and tourism industry always required vocational skills and practical experiences which professionals could not gain from other business sectors and universities. Therefore, the replacement of employees, regardless of their grading and positions, is significantly expensive due to the additional costs of training and professional development. The purpose of this study is to explore and understand the reasons and motivations that cause employees and professionals in the field of hospitality to remain. Based on the Social Cognitive Career Theory, the results indicated that the sense of belonging and the balance between family responsibilities and work served as two of the key themes for their career decision. The results of this study may indicate that hotel leaders, managers, human resources planners and employers should take the results of this study as the opportunity to reform, polish and develop their employee's satisfaction plan, training programmes and human resources planning in order to increase the satisfaction of their employees and reduce the turnover rate.
\end{abstract}

Keywords: career decision, hospitality, organisational psychology, replacement, sense of belonging, Social Cognitive Career Theory, tourism, turnover

\section{Introduction}

\subsection{Research background}

Human resources management in the hospitality and tourism industry is of the significant problems for the boards, employers, leadership, and managers. Research studies for human resources management in the field of hospitality and tourism management mainly focus on the job satisfaction of their employees (Ashton, 2018), the in-house and outsourced professional development of their inhouse employees (Wong \& Lee, 2017), and the how-to prevent frequent turnover of their in-house employees (Davidson et al., 2010).

Hospitality and tourism management is one of the rapid growth industries over the decades due to transportation developments (Prideaux, 200o). Unlike local businesses, restaurants and other leisure facilities, accommodation facilities are greatly needed as visitors and tourists usually do not have any living facilities at the destinations. Therefore, regardless of their budget and geographic planning, visitors and tourists need to have a place to stay. As a result, hotel and related living accommodation 
demands are increasing due to the changing of mid-and long-distance travelling. Europe, one of the most famous destinations with rich historical background and cultural perspective, more than a million visitors and tourists enter Europe for travelling, business trip and studying (Boluk et al., 2019). As a result, regardless of the region's economic developments, such as metropolitan, city, mid-size community or rural community, the living accommodation and related facilities should be established to meet the demands of visitors and tourists.

A significant concern of the current hospitality and tourism industry is frequent and high-level of employee turnover rate. Unlike other industries where employers may seek skilled professionals for replacement, the hospitality and tourism industry always required vocational skills and practical experiences which professionals could not gain from other business sectors and universities, such as skills and management abilities in the areas of housekeeping, reservation, front desk and even culinary arts (Afsar et al., 2018). Therefore, the replacement of employees, regardless of their grading and positions, is significantly expensive due to the additional costs of training and professional development. As a result, to reduce the turnover rate and frequent departure of employees, researchers indicated that employers and leadership should offer clear career promotion plans, professional development schemes, attractive packages, achievable evaluation and performance schemes, job security, and flexible plans for family and minorities (Hayes \& Ninemeier, 2009).

\subsection{Purpose of the study}

The purpose of this study is to explore and understand the reasons and motivations that cause employees and professionals in the field of hospitality to remain (Santhanam et al., 2017). In the current database, most of the research and projects tended to understand how to provide training and professional developments to attach the employees and recruit talented candidates from other organisations and industries from employers and leadership. Only a few research studies focus on these issues from the perspectives of employees and professionals. There are three significant points of this study.

First, human resource and workforce shortages in hospitality management, particularly the hotel industry, are significant. Hotels and resorts continued recruiting the appropriate employees for its expansion and loss due to the turnover decisions. Although recruitment may satisfy the human resource gaps, understanding turnover would be more important (Santhanam et al., 2017).

Second, many research and projects have been conducted on this issue. The findings were mostly reported in a quantitative form and from leadership, which could neglect the voices from the lowerlevel and the mid-level professional in the organisation. Therefore, there is a need to seek understanding and feedback from employees and professional workers who are working in the frontline departments. Also, qualitative research studies should seek in-depth sharing from these groups of frontline professionals in the hotel industry (Nieves \& Quintana, 2018).

Third, applications, implementations, and reforms to the international context and workplace are among the priorities of this study. In fact, the current research mainly focused on understanding the reasons and motivations that cause employees and professionals in the field of hospitality to remain, particularly in the hotel industry. However, the researcher provided applications and recommendations in the implementation chapter how the outcomes of this study may be beneficial for other for-profit and non-profit organisations and leadership, respectively. This study's outcomes may provide the blueprints, directions, and samples for potential reforms and professional development for the reforms in the field of school management, human resource management, and even government management.

In short, this study was being guided by one research question, as the following,

1) Why would mid-level and senior-level frontline hotel professionals decide to stay in the hospitality and tourism industry?

\subsection{Theoretical framework: The social cognitive career theory}

To understand the individuals' vocational directions, perspectives, and orientations, it is important to locate an appropriate model or theory to explore and discover the issue(s). During the 1990s, researchers 
in occupational psychology had created the Social Cognitive Career Theory (Lent et al., 1994; Lent \& Brown, 1996) to seek the relationships, understanding, perspectives, and feedback from individuals.

The Social Cognitive Career Theory (Lent et al., 1994; Lent \& Brown, 1996) was developed based on the Social Cognitive Theory (Bandura, 1986, 1989, 1995; Bandura \& Cervone, 1983). Originally, the Social Cognitive Theory advocated that individuals' behaviours are usually influenced by other individuals or environmental factors as their models. In other words, individuals tend to learn behaviours, actions, thinking, attitudes and practices based on models from their living environments. In human resources training and education, early studies indicated that individuals tend to learn knowledge and vocational skills from their master via apprenticeship and social cognitive theory (Guile \& Young, 1998). Based on apprenticeship ideas (Guile \& Young, 1998) and social cognitive theory (Bandura \& Cervone, 1986), the learners acquired knowledge, academic and vocational-oriented skills from observation, action study, and exercise from their teachers and trainers. Observational and practical training and exercise have echoed how learners gain their apprenticeship and social learning approach skills.

Based on the development of the Social Cognitive Theory and its ideas concerning about the learning as a form of social practice, skill, and exercise, researchers (Lent et al., 1994; Lent \& Brown, 1996), combined the notion of social cognitive approach with career decision and development. As a result, the Social Cognitive Career Theory has been created to understand how personal goals, educational achievement, and environmental/external factors. Individuals may be influenced by single and multiple factors (s) of their career decision. In 2019, a researcher (Dos Santos, 2019) had further indicated that financial considerations would be one of the significant factors or elements that may influence individuals' career decision and development. Therefore, to seek the wider interests and background of individuals' career decision and development, the current research study employed the Social Cognitive Career Theory based on the Dos Santos's recommendation (i.e. personal goals, educational achievement, financial considerations, and environmental/external factors) (Dos Santos, 2019). Figure 1 refers to the relationships and connections of the Social Cognitive Career Theory (Dos Santos, 2019).

Given the relative notions and applications about how personal goals, educational achievements, financial considerations, and environmental/external factors based on the Social Cognitive Career Theory (Dos Santos, 2019), this study employed the Social Cognitive Career Theory as the lens to understand the career decision, motivation and behaviours of a group of frontline hotel professionals in Europe.

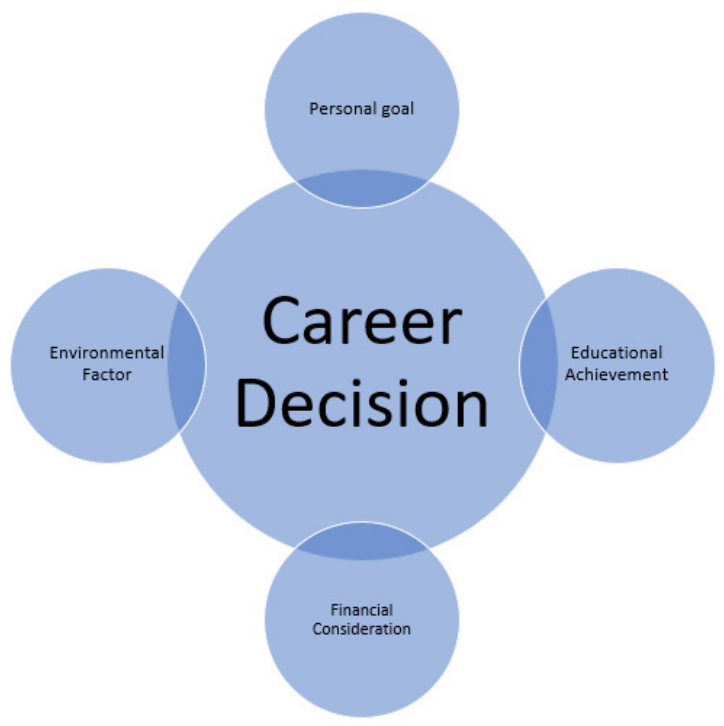

Figure 1. The relationship between career decision and Social Cognitive Career Theory (Dos Santos, 2019). 


\section{Methodology}

A qualitative methodology employing the applications of in-depth interviews would be appropriate for this study (Merriam, 2009). Because the goals of this study are to collect the in-depth understanding, stories, voices, and feedback of the participants in the hotel industry, asking the participants face-toface questions could capture the desired first-hand information without any misunderstanding from survey and questionnaire.

\subsection{Interpretivism}

Interpretivism is a meaningful and popular paradigm in hospitality and tourism research studies, particularly in hotel human resources management. The interpretivism provides the primary framework to guide the investigation of this study (Burrell \& Morgan, 1979). Researchers and scholars employed the interpretive paradigm in order to seek, understand and explore individuals' behaviours and actions via understanding their consciousness, personality, understanding, subjectivity from both the internal world and external environment of the participants. In other words, researchers and scholars tend to understand how these individuals describe their understand and social world. Behaviours are not a single factor but multiple factors which may be interconnected to different situations, backgrounds, sociocultural context, religious practices, and decision-making processes (Dos Santos, 2018). This investigation attempted to produce a holistic picture of hotel employees' career decision and development in the European Union.

\subsection{The application of the phenomenological approach}

Due to the geographic location and the numbers of participants, the researcher decides to employ the phenomenological approach (Moustakas, 1994) as the main tool to guide this study. The researcher first has considered the application of the case study (Yin, 2012). However, due to the nature of the case study, the researcher needs to collect data from a particular group of people with a similar background or a particular group of people in a similar location or organisation. As this study focuses on the overall performance and human resources problems in the European Union and the United Kingdom, the case study may limit the data information and recruitment progress due to the geographic restriction. On the other hand, the researcher has considered applying the narrative approach (Connelly \& Clandinin, 1990) for in-depth understanding and lived stories sharing. However, as the participants may not have significant lived stories and sharing that may influence and impact the overall development and performance of the human resources and hospitality and tourism industry in the European Union and the United Kingdom, the narrative approach may limit the data collection and confirmation of the information. Therefore, after careful consideration, the phenomenological approach was employed.

It is worth noting that the qualitative research tool was employed. The researcher decides to use the qualitative research tool with the following reasons. First, the qualitative research tool allows the researcher to collect face-to-face and in-depth interview and oral sharing from the participants.

Second, unlike the quantitative research tools, such as survey and questionnaires, the interview tool always allows the participants to share their real-life experiences, stories, understanding, feedback, and feelings without limitation. Also, the researcher catched up with some follow-up questions immediately after the sharing.

Third, in-depth and personal interview sessions are rich and meaningful. Unlike survey and questionnaires with numbers and statistics, participants are more likely to share their personal background and feeling with a real person instead of a survey checklist.

Based on the abovementioned, factors, the current qualitative research method with the application of the phenomenological approach matched the expectation and purpose of this study. 


\subsection{Participants and recruitment}

With a potential total of 30 participants $(\mathrm{N}=30)$, were invited to participate. It is worth noting that all participants need to agree to participate in this study. A research protocol was created based on this unique situation, directions of the study and the theoretical framework.

As the researcher does not have a strong connection to the industry all over the European Union member states and the United Kingdom, the researcher decided to employ the snowball sampling strategies for recruitment (Merriam, 2009). First, the researcher contacted three potential participants through an email invitation letter via a non-profit organisation in England, United Kingdom. After the in-depth interview of each participant, each participant should invite at least two participants who met the participant's criteria. The email invitation would provide information including the rationale and purpose of the study, the nature of data collection process, a declaration about their voluntary participation or non-participation, the protection of privacy, risk, and problems of this study. After several rounds of invitation from the snowball sampling strategies, 30 participants are targeted for participation. The following list outlines the criteria of the participants, which are,

(1) The participants need to have at least seven years of experience in the hotel industry;

(2) The participants are currently working at one of the hotels in one of the European member states and the United Kingdom;

(3) The participants should work in the same organisation for at least five years;

(4) The participants need to work at one of the hotel industry divisions, including but not limited to the front office, concierge, reservation, in-room dining, housekeeping, room service, butler service, hotel concourse. Although some large-size hotels may have general and administrative divisions, such as accounting and finance, human resources, marketing, and food and beverage, this research tended to collect data from participants from the divisions that are unique in the hotel industry.

\subsection{Data collection}

The researcher interviewed each participant individually in a semi-structure and one-on-one in-depth interview, with each interview lasting 6o-8o mins and being consistent with interviewing criteria. All the conversations and voices were be digitally recorded with an electronic recorder. After the researcher collects all voice information, the researcher transcribed the voice information into word transcripts. The transcripts were sent back to the participants for the member checking procedure to confirm the data information. As a result, all participants approved their transcripts and information.

First, all the interview sharing was audio-recorded. The researcher needed to transcribe the oral sharing to written transcripts to report the data information to the manuscript. As a result, nearly 200 pages of written transcripts were created.

Based on each participant's transcripts, the researcher sent the related materials to the participants for member checking procedure. As mentioned above, all approved their parts for further development.

\subsection{Data analysis}

Themes and categories that organise during the individual interviews were independently identified. The General Inductive Approach was employed for this study (Thomas, 2006). The inductive approach allows the researcher to understand the qualitative data information about the reasons and understanding why hotel professionals decided to remain in this high-turnover industry for at least five years.

The researcher followed a general inductive approach to narrow the large-size transcripts and data information into first-level themes by employing the open-coding technique (Creswell, 2007). Although the general inductive approach and its related techniques assist the narrowing research, the 
general inductive approach recommends that users further reduce the data information after the firstlevel themes. As a result, more than 20 themes were categorised based on the data information. However, qualitative researchers (Tang \& Dos Santos, 2017) indicated that qualitative data information should be narrowed and reduced to report meaningful findings. Therefore, the researcher decides to employ the axial coding technique (Creswell, 2007) to narrow the first-level themes into the secondlevel themes. For the overall procedures of the data analysis steps, please refer to Figure 2.

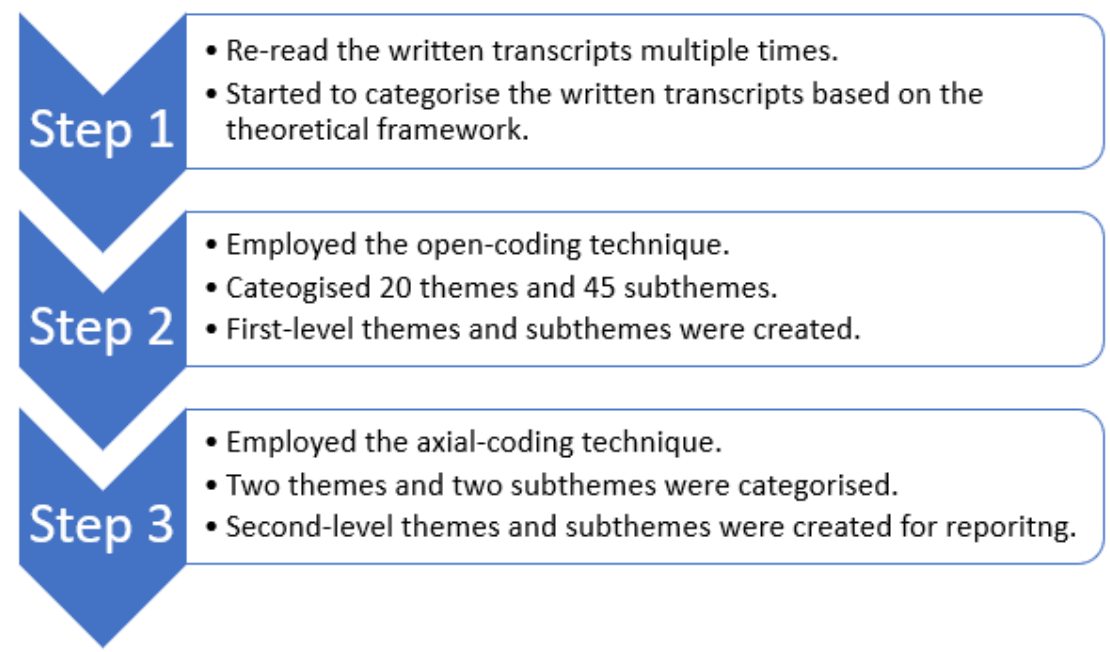

Figure 2. The data analysis procedure

\subsection{Human subject protection}

Due to the limited personnel in hospitality and tourism management in the European Union, confidentiality is the greatest concern of this study. The researcher makes every effort to protect the participants' personal information. Therefore, the researcher arranges for each participant to have a pseudonym. The researcher masks the real name, age, related education degree and qualification, nationality, and unrelated background of the participants due to the content form and agreement.

All signed and unsigned content forms and agreements, personal contacts, audio-recordings, transcripts, computers, and related materials were locked in a password-protected cabinet. Only the researcher has the rights to read the information. After the data analysis procedure, the researcher destroyed and deleted the related materials due to privacy reasons. All subjects were given their informed consent for inclusion before they participated in the study.

\section{Results and Discussions}

During each interview section, the participants answered the same general semi-structured questions that asked for their opinions and feedback. Although many participants worked in a similar organisation with the similar working responsibilities and backgrounds, the lived stories, managerial styles, co-workers, locations, sociocultural contexts and understanding about working responsibilities should not be the same. Therefore, after several rounds of data analysis, the researcher categorised two themes and two subthemes for reporting. In fact, one research question guided the direction of this study, which was why would mid-level and senior-level frontline hotel professionals decide to stay in the hospitality and tourism industry? Therefore, the themes and subthemes were categorised based on the lens of the Social Cognitive Career Theory and the research question of this study. Table 1 outlines 
the themes and subthemes of this study. To show the directed quote sharing, the researcher outlined the sharing as the following way (Participant \#, Department)

Table 1. A list of themes and subthemes

\begin{tabular}{|c|c|c|}
\hline \multicolumn{3}{|c|}{ Themes and subthemes } \\
\hline & & Senses of belonging \\
\hline & 4.1.1. & Positive working environment: Co-workers and leadership \\
\hline 4.2 . & 21 & Financial consideration \\
\hline
\end{tabular}

\subsection{Sense of belonging}

Based on the criteria, all participants have worked in the hotel profession for more than seven years, while at least five years in the same organisation. In human resources management, five years at the same organisation. In contrast to other business sectors, such as financial companies, retail shops, the fields of hospitality, tourism and hotel professions are unique which both organisational leaders and employees need to match their job features and skills. In other words, potential workforce and human resources are hard to find positions and vacancies that may require their working feature. Simultaneously, the leaders cannot replace the positions with staff without knowledge and skills in hotel operation (Afsar et al., 2018). Therefore, both parties (i.e. employers and employees) require matched skills and opportunities, limiting their career and operational development.

Therefore, many participants indicated that they are less likely to leave unless they could not afford the working environment once they sought an appropriate organisation and department for career development. Therefore, the following sharing reflects some previous studies (Dos Santos, 2016; Klassen et al., 2013; Vong \& Tang, 2017) about the appropriateness of workplace is one of the most important considerations that can increase the sense of belonging of the staff. Based on the lens of the Social Cognitive Career Theory (Lent et al., 1994), the personal goals take an important role to increase the sense of belonging of these groups of participants, as one said,

Although I cannot say I absolutely love my department and hotel, I like it as I can excel my skills and hotel knowledge and skills to my department and customers...I grew a lot when I worked at the same hotel...also, my hotel provides us with the opportunities to switch department for interdisciplinary working and learning...therefore, each staff has the chances to learn how to operate the daily management in our hotel...(Participant\#8, Housekeeping)

Besides the appropriateness and positive attitude about how their personal development matched the organisation and department (Bocanegra et al., 2016; Dos Santos, 2020a), many expressed their career development meet the expectation and direction of the organisation. Based on the Social Cognitive Career Theory (Lent et al., 1994), educational achievement and personal goals take the important roles in this category (Mccrory \& Thomson, 2019). For example, almost all participants expressed that their current organisation and department provide training and workshops to upgrade their skills and managerial leadership. Although many human resources departments offer similar courses and schemes for their employees, these participants told that these courses might lead to positive career promotion. Therefore, the sense of belonging was increased due to positive self-efficacy. A significant sharing was captured, like the following,

I think my organisation provides me with the opportunity...to promote my skills, to grow up as a leader...to exercise my abilities and leadership for the department...I enjoy this organisation and department because I can find my ways and myselffor both personal and career development (Participant\#6, Front Desk)

In short, based on the lens of the Social Cognitive Career Theory (Lent et al., 1994), many 
participants indicated that without the sense of belonging of their organisation and department, many might leave the hotel once they gained a better opportunity. However, the results indicated that positive and clear career promotion, effective training and workshop which may lead to potential promotion, and the working environment's appropriateness take important roles in this category. Based on some previous studies (Dos Santos, 2020a; Kim \& Seo, 2014), employees are more likely to stay at the same organisation due to the positive feedback and the sense of belonging of their department. Based on the participants' data, positive and clear career promotion, and effective training and workshop were some of the key elements.

\subsubsection{Positive working environment: Co-workers and leadership}

Besides the sense of belonging, many participants expressed that a positive working environment takes an important role in considering further career development and promotion in other organisations. According to a previous study (Karatepe, 2016), an effective supporting network among co-workers, organisations, and families always allows employees and staff to have a positive attitude toward their working environment. In fact, not all staff in the organisation have no family responsibilities. The worklife balance and support are one of the most important considerations in this area.

Based on the lens of the Social Cognitive Career Theory (Lent et al., 1994), environmental and external element takes an important role when individuals are considering their career decision and development. In this case, all participants expressed that a positive working environment and the effective relationship between their co-workers encouraged them to stay in the same organisation and department for further development (Karatepe, 2012). First, many expressed that supportive coworkers encouraged them to invest their future in the same department, a significant sharing was captured, as said,

Based on my experience and skills, I can apply to another organisation without a problem. But I enjoy the current working environment as I know all the team members very well. I would like to invest my future in this department and seek for career promotion at the same place...there are no guarantee if I can meet some similar supportive groups in the new organisation. But if the current place can offer me some career promotions, why not to stay? (Participant\#25, Butler)

In fact, based on the Social Cognitive Career Theory lens, environmental and external elements, in this case, the supportive co-workers' network, take an important role for the participants (i.e. decide to stay in the same organisation for long-term career development). With the reflection of previous studies (Self et al., 2020), if the co-workers are supportive, most team members tend to stay as they are all satisfied with the current situation and condition of their working environment.

Based on the lens of the Social Cognitive Career Theory (Lent et al., 1994) and the reflection of a previous study (Yang et al., 2012), the environmental and external factor takes an important role in this section. The previous study (Dos Santos, 2019, 202ob) indicated that negative managerial style always leads to higher-level turnover rate as most of their employees disagreed on the leadership and operation of their working environment. Once they have the opportunities, they will leave for a working environment which can excel their skills and abilities. For example, many participants used to work for organisations and departments which negative and aggressive leaders led. However, their experiences at the current working environment are positive, which make the comparison in between. As a result, many decided to stay as they believed the current working environment meets their long-term career development and investment expectations. A significant sharing was captured, like the following,

I agreed that if my director is a negative person who likes to play office politics, I will leave the office as soon as possible. However, my current supervisor is a very supportive and positive person who likes to help and train people with his skills from his previous experiences. A harmonised workplace should be a learning community instead of a political office...As I am still a learner, I want to stay, learn and excel my skills...(Participant\#12, Chef) 
In conclusion, the sense of belonging, positive working environment, and the supportive network between co-workers and managerial styles always take important roles in employees' retention issues in hospitality and tourism management (Karatepe, 2012, 2016; Li et al., 2019). Based on the lens of the Social Cognitive Career Theory (Lent et al., 1994), the conclusion of this theme and subtheme categorised that the environmental and external factors tend to lead individuals' understanding, career decision, career development, and the decision-making process. More importantly, these themes and subthemes explored that if employees are supported by the training and support networks from their co-workers and supervisors, they are more likely to stay in the same organisation due to the potential career promotion and job satisfaction (Ashton, 2018; Tzeng, 2002; Zeng et al., 2013). Although there is no guarantee that employees will not leave the position for various reasons, the results indicated that these elements effectively control the turnover rate among both positive and negative employees in the hotel profession.

\subsection{Financial consideration}

I stay in this hotel because I can earn additional incomes and bonuses due to my long-term commitment (Participant\#26, Butler).

Although many participants expressed that they are more likely to stay in the same organisation and department due to the positive and supportive working environment, all expressed the financial consideration and earning are their concerns. Many business organisations and NGOs like to provide annual bonuses and end-of-contract bonuses for those who have worked for the organisation as longterm employees. In other words, long-term employees who have contributed years of their career development in the same organisation may receive bonuses due to their years of experiences. In this case, all expressed that the long-term employees' bonus is one of the key elements for them to stay. A significant sharing was captured, as shown,

... as a long-term employee, I will receive additional bonuses, better compensation, childcare stipend and health insurance...although I may have a slightly higher salary for a senior-level position in another hotel...after I calculate and balance the overall package...I would decide to stay here...for both earning and my contribution to this hotel and department...(Participant\#1, Front Desk)

In short, many participants expressed different reasons and backgrounds about how financial considerations and resources make the important roles and positions for them to stay in the same organisation for more than five years. Based on the sharing, although a financial resource is one of the key elements, all expressed a positive attitude about their employers and managers(Penny Wan et al., 2014). It is worth noting that previous studies indicated that if the working environment is negative and aggressive, financial resources may not reduce the turnover rate for many working environments in the field of hospitality and tourism profession (Namasivayam et al., 2007). Based on the lens of the Social Cognitive Career Theory (Lent et al., 1994), financial consideration takes an important role based on the sharing from the participants.

\subsubsection{Balance between Family Responsibilities and Work}

From the sharing, particularly from female participants' perspective, many expressed that being a mother and full-time working professional is not easy. In this case, most of the participants were parents who need to have stable financial resources for their family and children. One of the biggest concerns of these participants is the balance between family responsibilities and work. First, a large group of participants believed that they have to manage family responsibilities, work and financial resources. Based on the current earning and income, they can manage their expectations due to their years of experiences and mid-level roles in the organisation. A significant sharing was captured, like the following, 
In balancing the family responsibilities and incomes, I think the hotel provides me a positive background...unlike many small businesses and motels, this hotel provides me some scholarships for my children...also, every month, the HR department may sponsor some storybooks for employees with children under eight years old...it is so encouraging (Participant\#7, Housekeeping)

In conclusion, based on the lens of Social Cognitive Career Theory, financial consideration is important. All expressed a different level of sharing and lived stories about how earning and incomes impact their career decision and decision-making process. With the reflection of previous studies (Namasivayam et al., 2007), individuals tend to seek career development and promotion not only about their salary but the overall package of benefits and compensation. In this case, many considered about their family responsibilities, stipend, annual bonuses and children's expenses. Many indicated that salary is not their only consideration when deciding their career development, but also how the organisation supports their family as a whole cohort and package. As a result, it is worth noting that employees tend to stay in the same organisation as long-term staff due to the overall benefit and supportive network of both employers and co-workers.

\section{Limitation and Future Research Directions}

Every study has its own limitations. In this study, the researcher advocated that four limitations should be upgraded in the future. First, the hospitality and tourism management is a wide field that involves many areas and industries. However, the current study only covered the voices and feedback from 30 participants working in the hotel profession. Therefore, future researchers should expand the study to other industries, such as event management, in order to outline the holistic picture and situation in the field.

Second, the current study only collected data information from participants in the European Union. In fact, hotel professionals and staff from other parts of the world may face similar human resources shortage and problems. Therefore, without larger data information, researchers, employers, policymakers, government leaders, and human resources planners may not understand how to manage their human resources problems effectively. Therefore, future researchers should collect wider research studies with international perspectives.

Third, the current study only covered the participants with qualitative research data collection tools and methods. In fact, mixed research studies with qualitative and quantitative research tools may better collect data from a wider population. Therefore, future research studies should employ mixed methodology and tools to collect data from a larger population.

Last but not least, the current study only covered the feedback and opinions from the employees and staff. However, the shareholders and employers' voices are also beneficial to upgrade the human resources situations and solve some unforeseen personnel problems in the working environment. Therefore, future research studies should collect data information from shareholders and employers to understand the overall performance and situation from both sides of the organisations.

\section{Conclusion}

The results of this study may indicate that hotel leaders, managers, human resources planners and employers should take the results of this study as the opportunity to reform, polish and develop their employee's satisfaction plan, training programmes and human resources planning in order to increase the satisfaction of their employees and reduce the turnover rate.

More importantly, many organisations in the field of hospitality and tourism management are facing reducing their customers due to the unforeseen circumstances. Therefore, it is a good time for leadership to reform, polish, and develop plans for their employees.

\section{Acknowledgement}

The study was supported by Woosong University Academic Research Funding 2021. 


\section{References}

Afsar, B., Shahjehan, A., \& Shah, S. I. (2018). Frontline employees' high-performance work practices, trust in supervisor, job-embeddedness and turnover intentions in hospitality industry. International Journal of Contemporary Hospitality Management, 30(3), 1436-1452. https://doi.org/10.1108/IJCHM-11-2016-0633

Ashton, A. S. (2018). How human resources management best practice influence employee satisfaction and job retention in the Thai hotel industry. Journal of Human Resources in Hospitality \& Tourism, 17(2), 175-199. https://doi.org/10.108o/15332845.2017.1340759

Bandura, A. (1986). Social foundations of thought and action: A social cognitive theory. Prentice-Hall.

Bandura, A. (1989). Regulation of cognitive processes through perceived self-efficacy. Developmental Psychology, 25, 729-735. http://dx.doi.org/10.1037/oo12-1649.25.5.729

Bandura, A. (1995). Comments on the crusade against the causal efficacy of human thought. Journal of Behavior Therapy and Experimental Psychiatry, 26, 179-190.

Bandura, A., \& Cervone, D. (1983). Self-evaluative and self-efficacy mechanisms governing the motivational effects of goal systems. Journal of Personality and Social Psychology, 45, 1017-1028.

Bandura, A., \& Cervone, D. (1986). Differential engagement of self-reactive influences in cognitive motivation. Organisational Behavior and Human Decision Processes, 38, 92-113.

Bocanegra, J. O., Gubi, A. A., \& Cappaert, K. J. (2016). Investigation of social cognitive career theory for minority recruitment in school psychology. School Psychology Quarterly, 31(2), 241-255. https://doi.org/10.1037/spqoooo142

Boluk, K. A., Cavaliere, C. T., \& Higgins-Desbiolles, F. (2019). A critical framework for interrogating the United Nations Sustainable Development Goals 2030 Agenda in tourism. Journal of Sustainable Tourism, 27(7), 847864. https://doi.org/10.1080/09669582.2019.1619748

Burrell, G., \& Morgan, G. (1979). Sociological paradigms and organisational analysis: Elements of the sociology of corporate life. Heinemann.

Connelly, F. M., \& Clandinin, D. J. (1990). Stories of experience and narrative inquiry. Educational Researcher, 19(5), 2-14. https://doi.org/10.3102/0013189Xo19005002

Creswell, J. (2007). Qualitative Inquiry and Research Design: Choosing Among Five Approaches. SAGE Publications.

Davidson, M. C. G., Timo, N., \& Wang, Y. (2010). How much does labour turnover cost? International Journal of Contemporary Hospitality Management, 22(4), 451-466. https://doi.org/10.1108/09596111011042686

Dos Santos, L. M. (2016). Relationship between turnover rate and job satisfaction of foreign language teachers in Macau. Journal of Educational and Developmental Psychology, 6(2), 125. https://doi.org/10.5539/jedp.v6n2p125

Dos Santos, L. M. (2018). Career decision of recent first-generation postsecondary graduates at a metropolitan region in Canada: A social cognitive career theory approach. Alberta Journal of Educational Research, 64(2), 141-152.

Dos Santos, L. M. (2019). Recruitment and retention of international school teachers in remote archipelagic countries: The Fiji experience. Education Sciences, 9(2), 132. https://doi.org/10.3390/educscigo20132

Dos Santos, L. M. (2020a). Stress, burnout, and turnover issues of Black expatriate education professionals in South Korea: Social biases, discrimination, and workplace bullying. International Journal of Environmental Research and Public Health, 17(11), 3851. https://doi.org/10.3390/ijerph17113851

Dos Santos, L. M. (2020b). The relationship between teachers and school professional staff's retention and managerial styles. Journal of Education and E-Learning Research, 7(1), 42-48. https://doi.org/10.20448/journal.509.2020.71.42.48

Guile, D., \& Young, M. (1998). Apprenticeship as a conceptual basis for a social theory of learning. Journal of Vocational Education \& Training, 5o(2), 173-193. https://doi.org/10.108o/13636829800200044

Hayes, D. K., \& Ninemeier, J. D. (2009). Human Resources Management in the Hospitality Industry. John Wiley \& Sons.

Karatepe, O. M. (2012). The effects of coworker and perceived organisational support on hotel employee outcomes. Journal of Hospitality \& Tourism Research, 36(4), 495-516. https://doi.org/10.1177/1096348011413592

Karatepe, O. M. (2016). Does job embeddedness mediate the effects of coworker and family support on creative performance? An empirical study in the hotel industry. Journal of Human Resources in Hospitality \& Tourism, 15(2), 119-132. https://doi.org/10.1080/15332845.2016.1084852

Kim, M. S., \& Seo, Y. S. (2014). Social cognitive predictors of academic interests and goals in South Korean engineering students. Journal of Career Development, 41(6), 526-546. https://doi.org/10.1177/0894845313519703

Klassen, R., Wilson, E., Siu, A. F. Y., Hannok, W., Wong, M. W., Wongsri, N., Sonthisap, P., Pibulchol, C., Buranachaitavee, Y., \& Jansem, A. (2013). Preservice teachers' work stress, self-efficacy, and occupational commitment in four countries. European Journal of Psychology of Education, 28(4), 1289-1309. https://doi.org/10.1007/s10212-012-0166-x 
Lent, R. W., \& Brown, S. D. (1996). Social cognitive approach to career development: An overview. The Career Development Quarterly, 44(4), 310-321. https://doi.org/10.1002/j.2161-0045.1996.tboo448.x

Lent, R. W., Brown, S. D., \& Hackett, G. (1994). Toward a unifying social cognitive theory of career and academic interest, choice, and performance. Journal of Vocational Behavior, 45(1), $79-122$. https://doi.org/10.1006/jvbe.1994.1027

Li, J. (Justin), Bonn, M. A., \& Ye, B. H. (2019). Hotel employee's artificial intelligence and robotics awareness and its impact on turnover intention: The moderating roles of perceived organisational support and competitive psychological climate. Tourism Management, 73(1), 172-181. https://doi.org/10.1016/j.tourman.2019.02.006

Mccrory, M., \& Thomson, T. (2019). The political is personal: Brexit and the career aspirations of Uk undergraduates. Journal of the National Institute for Career Education and Counselling, 42(1), 3-8. https://doi.org/10.20856/jnicec.4202

Merriam, S. B. (2009). Qualitative research: A guide to design and implementation. Jossey Bass.

Moustakas, C. (1994). Phenomenological research methods. Sage.

Namasivayam, K., Miao, L., \& Zhao, X. (2007). An investigation of the relationships between compensation practices and firm performance in the US hotel industry. International Journal of Hospitality Management, 26(3), 574587. https://doi.org/10.1016/j.ijhm.2006.05.001

Nieves, J., \& Quintana, A. (2018). Human resource practices and innovation in the hotel industry: The mediating role of human capital. Tourism and Hospitality Research, 18(1), 72-83. https://doi.org/10.1177/1467358415624137

Penny Wan, Y. K., Wong, I. A., \& Kong, W. H. (2014). Student career prospect and industry commitment: The roles of industry attitude, perceived social status, and salary expectations. Tourism Management, 40(1), 1-14. https://doi.org/10.1016/j.tourman.2013.05.004

Prideaux, B. (2000). The role of the transport system in destination development. Tourism Management, 21(1), 5363. https://doi.org/10.1016/So261-5177(99)0oo79-5

Santhanam, N., Kamalanabhan, T. J., Dyaram, L., \& Ziegler, H. (2017). Impact of human resource management practices on employee turnover intentions. Journal of Indian Business Research, 9(3), $212-228$. https://doi.org/10.1108/JIBR-10-2016-0116

Self, T. T., Gordon, S., \& Ghosh, A. (2020). Increasing management retention: The mediating role of organisational embeddedness on coworker support and turnover intention. International Journal of Hospitality $\mathcal{E}$ Tourism Administration, 1-19. https://doi.org/10.1080/15256480.2019.1708224

Tang, K. H., \& Dos Santos, L. M. (2017). A brief discussion and application of interpretative phenomenological analysis in the field of health science and public health. International Journal of Learning and Development, 7(3), 123-132. https://doi.org/10.5296/ijld.v7i3.11494

Thomas, D. R. (2006). A general inductive approach for analysing qualitative evaluation data. American Journal of Evaluation, 27(2), 237-246. https://doi.org/10.1177/1098214005283748

Tzeng, H.-M. (2002). The influence of nurses' working motivation and job satisfaction on intention to quit: an empirical investigation in Taiwan. International Journal of Nursing Studies, 39(8), 867-878. https://doi.org/10.1016/Soo20-7489(02)00027-5

Vong, L. T.-N., \& Tang, W. S.-L. (2017). The mediating effect of work-family conflict in the relationship between job stress and intent to stay: The case of tourism and hospitality workers in Macau. Journal of Human Resources in Hospitality \& Tourism, 16(1), 39-55. https://doi.org/10.1080/15332845.2016.1202056

Wong, S., \& Lee, P. (2017). Roles of the hotel training professionals: Perspectives of industry practitioners. International Journal of Hospitality $\mathcal{E}$ Tourism Administration, 18(1), 61-83. https://doi.org/10.108o/15256480.2016.1263171

Yang, J.-T., Wan, C.-S., \& Fu, Y.-J. (2012). Qualitative examination of employee turnover and retention strategies in international tourist hotels in Taiwan. International Journal of Hospitality Management, 31(3), 837-848. https://doi.org/10.1016/j.ijhm.2011.10.001

Yin, R. K. (2012). Applications of Case Study Research (3rd ed.). SAGE Publications.

Zeng, Z., Forrest, D., \& McHale, I. G. (2013). Happiness and Job Satisfaction in a Casino-Dominated Economy. Journal of Gambling Studies, 29(3), 471-490. https://doi.org/10.1007/s10899-012-9318-9 